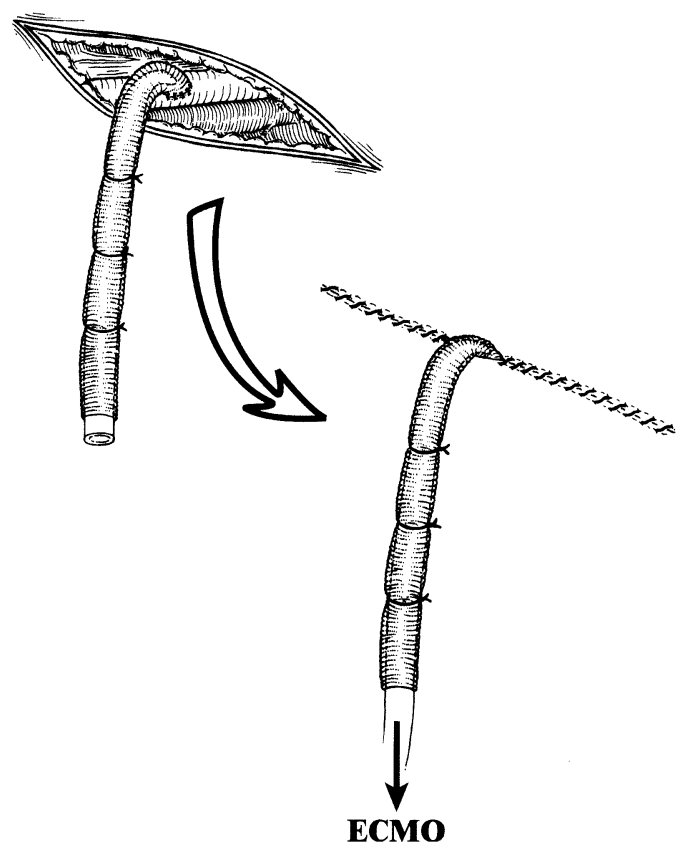

Figure 2

axillary artery is usually free of atherosclerotic disease. This approach maintains perfusion to the extremities and provides antegrade blood flow directly to the ascending aorta. Oxygenated blood is delivered to the brain and the coronary arteries, where it is needed the most.

Another unique advantage is the ability to close the chest, which minimizes the risk of mediastinitis and also decreases ongoing hemorrhage from the sternal edges. In case of bleeding complications at the cannulation sites, local wound exploration can easily be performed at the bedside.

We have now used this method in 5 patients, with no complications related to the technique of cannulation. This remains our preferred approach for ECMO support. In cases in which there is excessive chest wall edema or in morbidly obese patients in whom dissection of the axillary artery might be problematic, the same technique can be applied to the common femoral artery.

\section{References}

1. Smedira NG, Moazami N, Golding CM, McCarthy PM, AppersonHansen C, Blackstone EH, et al. Clinical experience with 202 adults receiving extracorporeal membrane oxygenation for cardiac failure: survival at five years. $J$ Thorac Cardiovasc Surg. 2001;122:92-102.

2. Pagani FD, Aaronson KD, Swaniker F, Bartlett RH. The use of extracorporeal life support in adult patients with primary cardiac failure as a bridge to implantable left ventricular assist device. Ann Thorac Surg. 2001;71(suppl 3):77-85.

3. Sabik JF, Lytle BW, McCarthy PM, Cosgrove DM. Axillary artery: an alternative site of arterial cannulation for patients with extensive aortic and peripheral vascular disease. J Thorac Cardiovasc Surg. 1995;109: $885-91$.

\title{
Left-sided cervical aortic arch aneurysm: Case report
}

\author{
Kazuhiko Higuchi, MD, ${ }^{a}$ Kenzi Koseni, MD, ${ }^{a}$ and Shinichi Takamoto, MD, ${ }^{b}$ Chiba and Tokyo, Japan
}

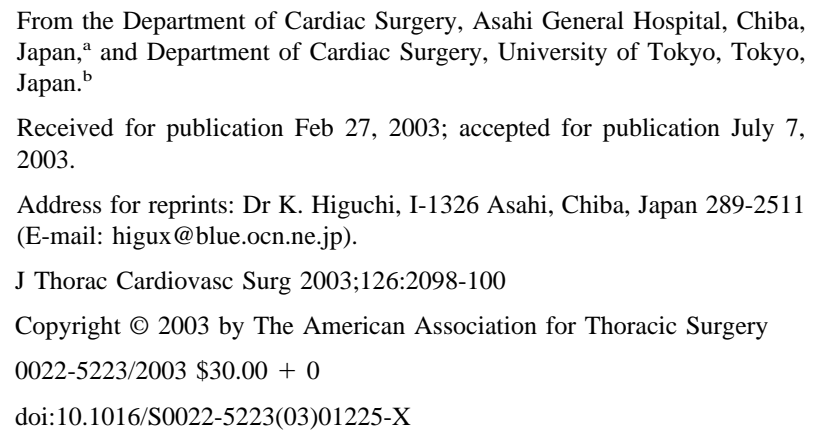

From the Department of Cardiac Surgery, Asahi General Hospital, Chiba, Japan, $^{\mathrm{a}}$ and Department of Cardiac Surgery, University of Tokyo, Tokyo, Japan. $^{\text {b }}$

Received for publication Feb 27, 2003; accepted for publication July 7, 2003.

Address for reprints: Dr K. Higuchi, I-1326 Asahi, Chiba, Japan 289-2511 (E-mail: higux@blue.ocn.ne.jp).

J Thorac Cardiovasc Surg 2003;126:2098-100

Copyright $\odot 2003$ by The American Association for Thoracic Surgery $0022-5223 / 2003 \$ 30.00+0$

doi:10.1016/S0022-5223(03)01225-X

pathologic findings in surgical series support the indication for surgical intervention. ${ }^{2}$

\section{Clinical Summary}

A 16-year-old woman was admitted to Asahi General Hospital with a pulsatile mass in the left neck. Blood pressure was 110/60 $\mathrm{mm} \mathrm{Hg}$ in the right arm and 90/60 $\mathrm{mm} \mathrm{Hg}$ in the left arm. Examination of the neck revealed a visible 4-cm pulsatile mass in the left supraclavicular region. A thrill with a grade II/VI bruit was noted over the left carotid artery. Chest radiography revealed a smooth left-sided mediastinal mass. Three-dimensional computed tomography (3D-CT), magnetic resonance angiography (MRA), and aortography revealed a saccular aneurysm of the cervical aortic arch just distal to the origin of the left carotid artery, with normal branching. An aberrant and torturous left subclavian artery originated from the distal end of the aneurysm (Figure 1).

\section{Surgical Technique}

The aortic arch, the descending aorta, and the left subclavian artery were accessed via a left thoracotomy in the fourth intercostal space. The left superior vena cava was dissected from the aneu- 

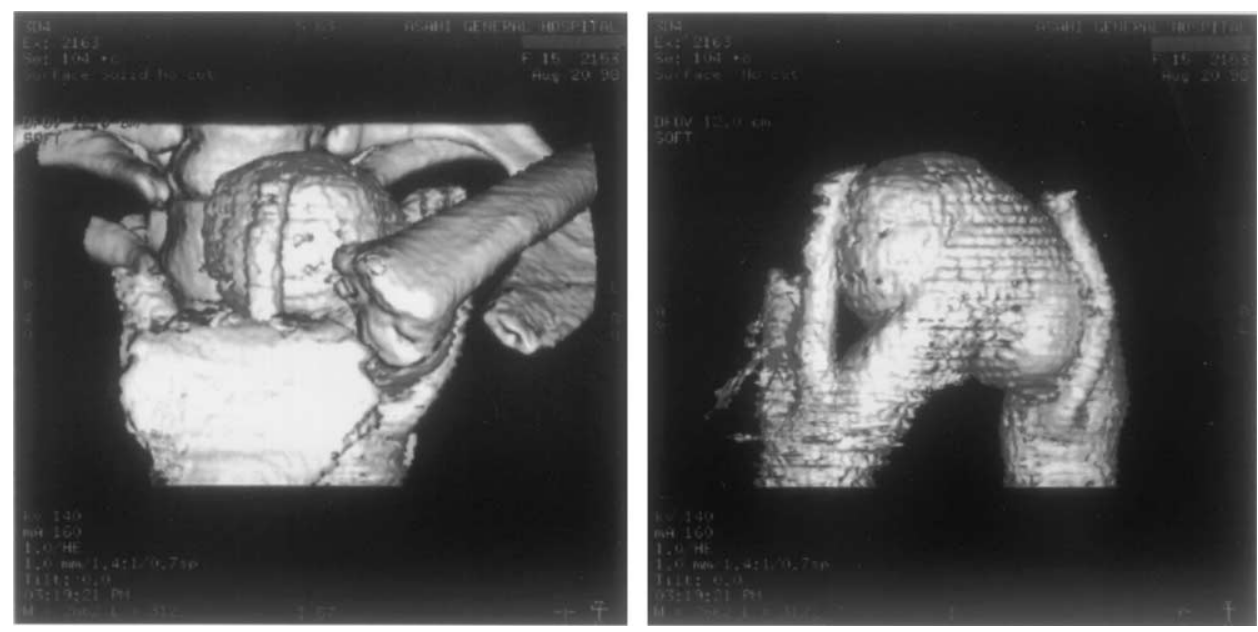

Figure 1. Preoperative 3D-CT shows a cervical aortic arch aneurysm.

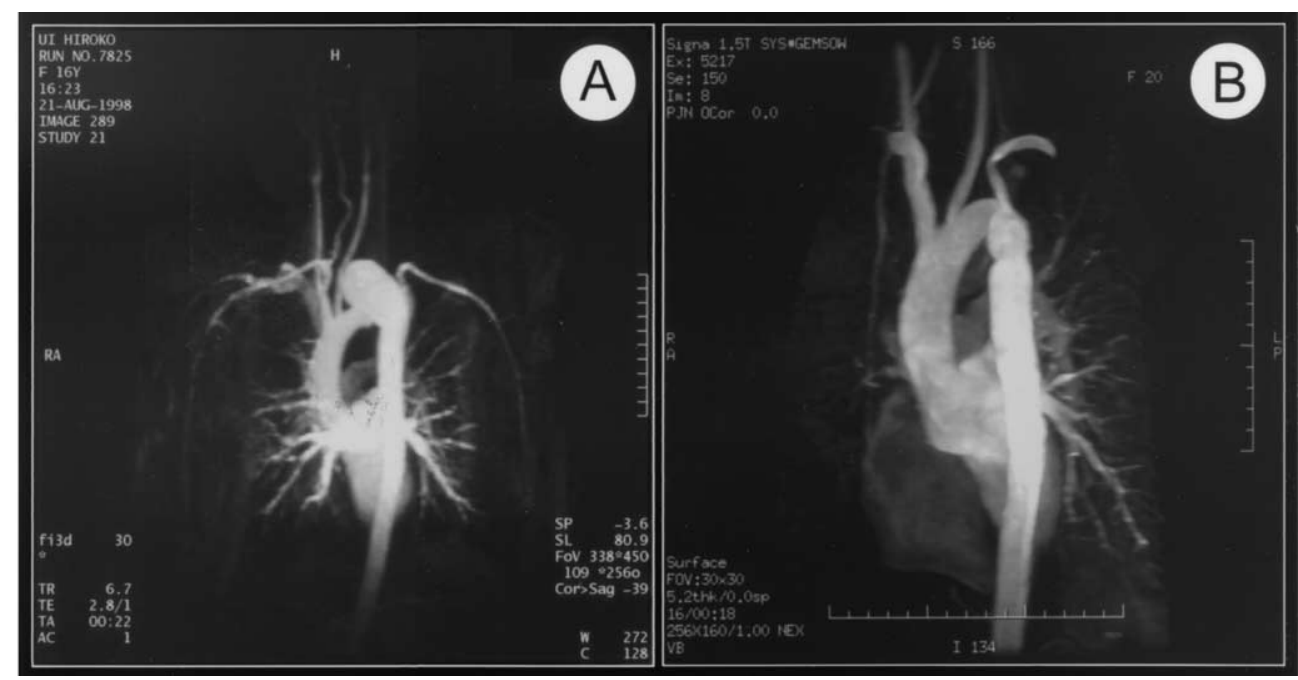

Figure 2. A, Preoperative MRA demonstrates a cervical aortic arch aneurysm between the left carotid artery and the left subclavian artery. B, An MRA performed 4 years after the operation demonstrates successful treatment of the aneurysm by the graft replacement procedure.

rysm. After systemic heparinization (200 IU/kg body weight), the descending aorta and inferior vena cava were cannulated, and partial cardiopulmonary bypass was established. After core cooling to a rectal temperature of $34^{\circ} \mathrm{C}$, the aorta was then clamped just distal to the left carotid artery and the descending aorta, after which the subclavian artery was clamped and divided. The aneurysm was excised, and a 22-mm Hemashield graft (woven double velour graft; Boston Scientific, Natick, Mass) was anastomosed in an end-to-end fashion. The aberrant subclavian artery was reconstructed to the side of the graft by using an interposed $8-\mathrm{mm}$ Hemashield graft. Pathologic examination revealed cystic medial degeneration of the aortic arch. Deletion of chromosome $22 q 11$ was not detected in genetic analysis. The postoperative course and 4-year follow-up were uneventful (Figure 2).

\section{Comment}

Cervical arch abnormalities are not that rare to experienced, highvolume thoracic aortic surgeons and are common in patients with a bicuspid aortic valve. However, this condition is rarely reported or discussed in the literature. Cervical aortic arch was first described in 1914, and it was postulated that the anomaly arises from an abnormal persistence of the third aortic arch and the regression of the fourth arch, which normally forms the aortic arch. ${ }^{3}$ The pathophysiology of aneurysmal dilatation is unknown. Most patients with this malformation are asymptomatic but patients may have symptoms of vascular compression of the esophagus and trachea, which manifest as dysphagia, dyspnea, or frequent pulmonary infections. Dysphagia and respiratory distress are associated with a right-sided cervical arch, whereas aneurysmal forma- 
tions are more often associated with a left-sided cervical arch. Physical examination reveals a large pulsatile mass in the supraclavicular region. ${ }^{4}$ 3D-CT, angiography and MRA are useful for definite diagnosis and surgical treatment.

Deletion of chromosome 22q11 was recently reported in some cases of cervical aortic $\operatorname{arch}^{5}$ but was not evident in this case. The female predilection for aneurysm formation is consistent with a genetic factor. ${ }^{1}$

The pathologic finding of cystic medial degeneration in the aneurysm has been reported in a large surgical series and supports the importance of recognition and surgical intervention in this condition, whether patients are symptomatic or not. ${ }^{2}$

\section{References}

1. Farsak B, Yilmaz M, Kaplan S, Böke E. Cervical aortic arch with aneurysm formation. Eur J Cardiothorac Surg. 1998;14:437-9.

2. Cooly DA, Mullins CE, Gooch JB. Aneurysm of right-sided cervical arch; surgical removal and graft replacement. J Thorac Cardiovasc Surg. 1976;72:106-8.

3. Reid DG. Three examples of a right aortic arch. J Anat Physiol. 1914;48:174-81.

4. Morris R, Ruttley M. Left cervical aortic arch associated with aortic aneurysm. Br Heart J. 1978;40:87-90.

5. Kumar A, McCombs JL, Sapire DW. Deletions in chromosome 22q11 region in cervical aortic arch. Am J Cardiol. 1997;79:38890.

\section{Mechanical support of the unrepaired postinfarction ventricular septal defect with the Abiomed BVS $\mathbf{5 0 0 0}$ ventricular assist device}

Louis E. Samuels, MD, John C. Entwistle III, MD, Elena C. Holmes, CRNP, Ted Parris, MD, and Andrew S. Wechsler, MD, Philadelphia, $\mathrm{Pa}$

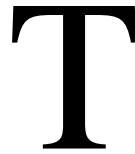
he Abiomed BVS 5000 (Abiomed, Inc, Danvers, Mass) is an extracorporeal pneumatic ventricular assist device (VAD) that has been used in a variety of acute cardiac conditions. ${ }^{1}$ The purpose of this report is to describe the use and cannulation strategy of the BVS $5000 \mathrm{VAD}$ as a bridge to transplantation in a case of unrepaired postinfarction ventricular septal defect (VSD).

\section{Clinical Summary}

A 62-year-old American man with a history of coronary artery disease had a myocardial infarction while in the Dominican Republic on September 6, 2001. On September 11, 2001, he became hypotensive from reinfarction. Physical examination revealed a new heart murmur. An echocardiogram showed a posterior ventricular VSD. He was given intravenous dopamine and prepared for transfer to the United States for further management. As a result of the World Trade Center attack, air transportation was suspended. On September 13, 2001, permission was granted for an emergency flight to Philadelphia. The patient was in cardiogenic shock with multiple organ system failure. He was intubated, he

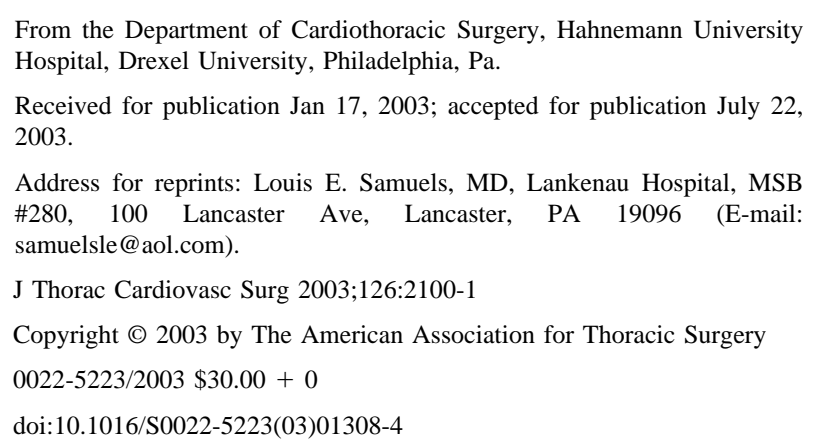

TABLE 1. Oxygen saturations and hemodynamic variables before and after VAD placement

\begin{tabular}{lcc}
\hline & Before VAD & After VAD \\
\hline Oxygen saturation & & \\
$\quad$ Right atrium & $60 \%$ & $58 \%$ \\
Right ventricle & $93 \%$ & $62 \%$ \\
Pulmonary artery & $82 \%$ & $63 \%$ \\
$\quad$ Aorta & $95 \%$ & $100 \%$ \\
Systemic blood pressure (mm Hg) & $80 / 50$ & $152 / 86$ \\
Pulmonary arterial pressure (mm Hg) & $55 / 33$ & $24 / 14$ \\
Central venous pressure (mm Hg) & 28 & 12 \\
Cardiac output (L/min) & 3.4 & 5.3 \\
\hline
\end{tabular}

was given additional inotropic and vasoconstrictive drugs, and an intra-aortic balloon pump was inserted. The catheterization showed severe-triple vessel coronary artery disease (poor runoff) with moderate pulmonary hypertension and a large posterior VSD. The right atrial, right ventricular, and pulmonary artery saturations demonstrated a shunt at the ventricular level (Table 1). The patient was transferred to the operating room for management.

The patient was placed on cardiopulmonary bypass with mild hypothermia. The heart showed minimal contractility and a massive acute posterior wall myocardial infarction. The decision was made to place the Abiomed VAD without repairing the VSD or bypassing the coronary arteries. Inflows to the blood pumps were established at the atrial level and outflows were to the great arteries. The patient was weaned from cardiopulmonary bypass with excellent hemodynamic and mechanical support $(5 \mathrm{~L} / \mathrm{min})$. The patient was transported to the cardiothoracic intensive care unit in stable condition, with elimination of the shunt (Table 1).

After the operation, the patient awoke with an intact neurologic status and stable vital signs. He remained on VAD support for 8 